\title{
EL ARTE DE ALMADA NEGREIROS COMO EJEMPLO DE LA CONEXIÓN ENTRE HISTORIA, MATEMÁTICAS Y ARTE
}

\author{
Cristina Lúcia Dias Vaz ${ }^{1}$ \\ cvaz@ufpa.br \\ Edilson dos Passos Neri Júnior ${ }^{1}$ \\ neri@ufpa.br \\ ${ }^{1}$ Universidade Federal do Pará, Brasil
}

Recibido: 15/10/2019 Aceptado: 08/01/2020

\section{Resumen}

Este artículo es un extracto de la tesis de maestría Actos y lugares de aprendizaje creativo en matemáticas. Nuestro objetivo es presentar las potencialidades de las interconexiones entre Historia, Matemáticas y Arte, como conocimiento que puede integrarse con los lenguajes innovadores que ofrecen las tecnologías de la información y la comunicación para permitir la movilización de este conocimiento de manera híbrida, para reorientar los enfoques didácticos en la enseñanza de las Matemáticas desde un enfoque interdisciplinario. Para lograr este objetivo, adoptamos el método de cartografía como un método de investigación anclado en la propuesta de cartografía de los filósofos Gilles Deleuze y Félix Guattari; El concepto de aprendizaje creativo inspirado en las ideas del educador Paulo Freire y el psicoanalista Donald Winnicott y el concepto de interdisciplinariedad propuesto por Ivani Fazenda. Los resultados de esta investigación apuntan a la historia de las matemáticas como un elemento que impregna la búsqueda de un proceso de aprendizaje creativo de manera transversal, estableciendo un diálogo entre las matemáticas y el arte.

Palabras clave: Aprendizaje Creativo, Matemáticas, Arte, Historia de las Matemáticas, Almada Negreiros.

\section{THE ART OF ALMADA NEGREIROS AS AN EXAMPLE OF THE CONNECTION BETWEEN HISTORY, MATHEMATICS AND ART}

\begin{abstract}
This article is an excerpt from the master's thesis Acts and Places for Creative Learning in Mathematics. The main objective is to present potentialities of the interconnections between History, Mathematics and Art, as knowledge that can be integrated with the innovative languages offered by information and communication technologies in order to enable the mobilization of this knowledge in a hybrid way, to reorient didactic approaches in teaching mathematics from an interdisciplinary approach. To achieve this goal, we adopted the cartography method as a research method anchored in the proposal of cartography by the philosophers Gilles Deleuze and Félix Guattari; in the concept of creative learning inspired by the ideas of educator Paulo Freire and psychoanalyst Donald Winnicott; and in the concept of interdisciplinarity proposed by Ivani Fazenda. The results of this research pointed to the
\end{abstract}


history of mathematics as an element that permeated the search for a creative learning process in a transversal way, as so to establish a dialogue between Mathematics and Art.

Keywords: Creative Learning, Math, Art, History of Mathematics, Almada Negreiros.

\section{A ARTE DE ALMADA NEGREIROS COMO EXEMPLO DE CONEXÃO ENTRE HISTÓRIA, MATEMÁTICA E ARTE}

\section{Resumo}

Este artigo é um recorte da dissertação de mestrado Atos e Lugares de Aprendizagem Criativa em Matemática. O principal objetivo é apresentar potencialidades das interconexões entre História, Matemática e Arte, como saberes que podem se integrar às linguagens inovadoras oferecidas pelas tecnologias de informação e comunicação no sentido de possibilitar a mobilização desses saberes de forma híbrida, para reorientar as abordagens didáticas no ensino de matemática sob um enfoque interdisciplinar. Para alcançar este objetivo, adotamos método da cartografia como método de pesquisa ancorado na proposta de cartografia dos filósofos Gilles Deleuze e Félix Guattari; no conceito de aprendizagem criativa inspirado nas ideias do educador Paulo Freire e do psicanalista Donald Winnicott; e no conceito de interdisciplinaridade proposto por Ivani Fazenda. Os resultados desta pesquisa apontaram para a história da matemática como elemento que perpassou a busca de um processo de aprendizagem criativa de forma transversal, de modo a estabelecer um diálogo entre a Matemática e Arte.

Palavras-chave: Aprendizagem Criativa, Matemática, Arte, História da Matemática, Almada Negreiros.

\section{Introdução}

Este artigo surge a partir de um encontro, ou melhor, de um lugar. Um lugar com múltiplas e infinitas entradas e saídas, compreendido como centro de significados construídos pela experiência (Tuan, 2018), que nos proporcionou encontros com a criatividade e a interdisciplinaridade, através da Arte e da Matemática. Nosso objetivo é apresentar potencialidades das interconexões entre História, Matemática e Arte, como saberes que podem se integrar às linguagens inovadoras oferecidas pelas tecnologias de informação e comunicação no sentido de possibilitar a mobilização desses saberes de forma híbrida, para reorientar as abordagens didáticas no ensino de matemática sob um enfoque interdisciplinar.

Para melhor situar o leitor, consideramos importante situar que este artigo se originou de uma pesquisa que teve como finalidade principal obter informações para a elaboração de uma dissertação de mestrado intitulada Atos e Lugares de Aprendizagem Criativa em Matemática (Neri Júnior, 2019), na qual investigamos como algumas ações interdisciplinares podem promover uma aprendizagem criativa em matemática. Esta investigação transcorreu 
apoiada sob o pilar da cartografia como método de pesquisa, ancorado na proposta de cartografia dos filósofos Gilles Deleuze e Félix Guattari (1995); o conceito de aprendizagem criativa inspirado nas ideias de Paulo Freire (2011) e do psicanalista Donald Winnicott (2011) e o conceito de interdisciplinaridade proposto por Ivani Fazenda. Enquanto pesquisadorescartógrafos, buscamos experiências interdisciplinares em lugares - a Garagem, o Atelier e a Casa Gardner - não necessariamente reais, tendo em vista a aprendizagem criativa. Em específico, neste artigo, queremos apresentar as experiências vivenciadas no Atelier, um espaço estimulante e inspirador para promover uma aprendizagem criativa em Matemática em constante diálogo com a Arte.

O Atelier, enquanto este lugar de múltiplas entradas e saídas, nos permite transitar pelos caminhos da aprendizagem, da criatividade e/ou da interdisciplinaridade, contudo, queremos neste artigo seguir por um caminho diferente, que agora se revelara para nós: a história da matemática. Nosso objetivo é apresentar algumas aproximações entre a história da matemática e a arte, que identificamos em neste caminhar.

Para o desenvolvimento desta investigação, buscamos um método que valorizasse as múltiplas direções de uma pesquisa, que fosse aberto à experimentações e que não representasse apenas um objeto, mas também que nos permitisse compreender todo o processo, não como expectadores na plateia, mas como atores em cena. Encontramos no método da cartografia esta possibilidade, que advém do conceito de rizoma, apresentado pelos filósofos Deleuze e Guattari na Introdução de Mil Platôs (1995). Para fundamentar sua teoria, os filósofos apropriam-se do conceito biológico de rizoma ${ }^{1}$ e o transpõem para filosofia propondo, dessa forma, um processo de investigação que possui múltiplas direções. Um rizoma, para Deleuze e Guattari (1995), não é feito de unidades, mas de dimensões, ou antes de direções movediças. Ele não tem começo nem fim, mas sempre um meio pelo qual ele cresce e transborda. Ele constitui multiplicidades lineares a $n$ dimensões, sem sujeito nem objeto, exibíveis num plano de consistência e do qual o Uno é sempre subtraído (n-1).

Para uma melhor compreensão da ideia de rizoma, Deleuze e Guattari (1995) elencaram os seguintes princípios:

\footnotetext{
${ }^{1} \mathrm{O}$ rizoma consiste numa estrutura presente em algumas plantas cujos brotos podem ramificar-se em qualquer ponto e transformar-se em um bulbo ou um tubérculo.
} 
a) Princípio de conexão e de heterogeneidade: qualquer ponto do rizoma pode ser conectado a qualquer outro e deve sê-lo, diferenciando-o de uma árvore, por exemplo, em que há um ponto fixo. No rizoma, não há começo ou fím e, os pontos do rizoma conectam-se sem uma ordem anteriormente estabelecida.

b) Princípio da multiplicidade: num rizoma, inexiste a unidade, no sentido que tanto o objeto, quanto o sujeito não são únicos.

c) Princípio de ruptura a-significante: um rizoma pode ser segmentado ou quebrado em qualquer lugar. Pode ser também reconstituído em suas linhas, em qualquer lugar. Mesmo quando um rizoma é segmentado, as linhas onde ocorreram tal segmentação também fazem parte do rizoma e nestas linhas podem encontrar elementos que reconstituem o rizoma.

d) Princípio da cartografia e da decalcomania: o rizoma não segue um modelo de estrutura ou gerativo. Ele é diferente de um decalque, que segue um padrão de reprodução. O rizoma é como um mapa: é aberto, é conectável em todas as suas dimensões, desmontável, reversível, suscetível de receber modificações constantemente.

Desta forma, é neste quarto princípio que encontramos a possibilidade de entender o funcionamento do modelo rizomático como método de análise de um processo, de modo a orientar o pesquisador-cartógrafo no campo de pesquisa.

No Brasil, o método da cartografia é utilizado em pesquisas no campo da arte, da saúde, das ciências humanas e sociais, sempre na direção de acompanhar processos e produzir subjetividade. Os estudos mais sistemáticos da cartografia, no campo da pesquisa qualitativa, ocorrem a partir de 2005 quando um grupo de professores se debruçou para elaborar um conjunto de pistas para nortear este método e, em 2009, publicaram a obra Pistas do método da cartografia: Pesquisa-intervenção e produção de subjetividade, sistematizada por Eduardo Passos, Virgínia Kastrup, Liliana da Escóssia e Silvia Tedesco e outros pesquisadores. Assim, esta publicação será referência na construção desta pesquisa.

Como método de pesquisa, a cartografia parte do pressuposto que não há regras e objetivos previamente estabelecidos ou que o trabalho do pesquisador se faz a partir de um algoritmo. Passos e Barros (2015, p. 17) apontam "a diretriz cartográfica se faz por pistas que 
orientam o percurso da pesquisa sempre considerando os efeitos do processo do pesquisar sobre o objeto da pesquisa, o pesquisador e seus resultados".

Com esta perspectiva, o caminhar desta pesquisa seguiu em busca de um processo de aprendizagem criativa em matemática, que valorizasse a autonomia do aprendiz e suas potencialidades para imprimir uma marca própria neste processo. Para compreender o sentido de aprendizagem criativa, recorremos às concepções de criatividade e aprendizagem, segundo Donald Winnicott (2011) e Paulo Freire (2011), respectivamente.

Para o psicanalista inglês Donald Winnicott, a criatividade relaciona-se com a própria existência do indivíduo, em uma experiência saudável de estar/sentir-se vivo e não está associada ao ter ou não um talento especial. Winnicott (1975 apud SAKAMOTO, 2012), postula que a criatividade é influenciada pelas experiências vivenciadas pelo ser humano no início da vida quando ainda é um bebê. Ele compreende que um "ambiente suficientemente bom" promove o desenvolvimento do potencial criativo no indivíduo e que o "brincar" é um dos fatores principais relacionado com a criatividade, pois o brincar é uma comunicação e uma experiência criativa, que o indivíduo (criança ou adulto), pode utilizar sua personalidade integral. Ao escrever sobre o pensamento winnicottiano, Pires (2010, p. 59) afirma que nas fases posteriores do amadurecimento, este brincar assume outras formas. Por exemplo, a arte é uma forma de brincar do adulto, pois ao realizar uma produção artística, o adulto pode encontrar nisto o prazer do viver criativamente.

Winnicott (2011, p. 22) entende que, independente de qual definição de criatividade a que se chegue, "ela deve incluir a ideia de que a vida vale a pena - ou não - ser vivida, a ponto de a criatividade ser - ou não - uma parte da experiência de vida de cada um". Assim, para que um indivíduo seja criativo, basta que ele exista e tenha consigo o sentimento de existência, na perspectiva de ser capaz de criar o mundo e de interceptar a realidade com o seu toque pessoal, através da imaginação. Viver criativamente é, portanto, recriar com um toque próprio aquilo que já existe.

Neste contexto do viver criativamente, entendemos que o ambiente escolar pode ser, em específico, um local para que o indivíduo seja criativo e desfrute desta experiência de sentir-se vivo e de modificar a realidade com seu toque pessoal. Paulo Freire (2011) considera a educação como processo permanente, que tem sua origem quando nos percebemos como seres inacabados e em constante formação. Este estado de "inacabamento" do indivíduo é 
próprio da experiência de ser/estar vivo, que desencadeia um processo contínuo de aprendizagem.

Ao afirmar que aprender não se dá a partir da transferência de conhecimento entre quem ensina e quem aprende, mas sim através de um processo de construção do conhecimento, que começa no próprio aprendiz, Paulo Freire nos leva a refletir que o processo de criação é mais rico e eficaz que o processo de repetição. Para Freire $(2011$, p.48) aprender "é construir, reconstruir, constatar para mudar, o que não se faz sem abertura ao risco e à aventura do espírito", ou seja, a liberdade e autonomia são características fundamentais no processo de aprendizagem.

Quando compreendemos que a criatividade está associada ao a capacidade de a "tudo olhar com se fosse a primeira vez", é possível estabelecer aproximações entre a teoria de Winnicott (2011) e as concepções pedagógicas de Paulo Freire (2011), observando que esse olhar de descoberta é essencial para despertar o encantamento do aprendiz, que o ambiente escolar é fundamental para estimular a criatividade e potencializar um aprendizado original e autônomo que possibilite ao aprendiz criar ou recriar o mundo ao seu redor, transformando-o e transformando a si mesmo. Portanto, entendemos aqui que a aprendizagem criativa, inspirados em Donald Winnicott (2011) e Paulo Freire (2011), acontece quando o aprendiz desfruta da experiência de estar vivo, desfruta do prazer da descoberta e, consciente da sua incompletude, vai em busca de um aprendizado que o possibilite criar ou recriar conhecimento de forma autônoma, imprimindo a sua marca pessoal no processo.

Diante disto, ao longo da caminhada em busca de um processo de aprendizagem criativa em matemática, nos deparamos com várias possibilidades de trajetórias, tais como o movimento "faça você mesmo", o lúdico pelo simples prazer de resolver problemas e o interdisciplinar entre a matemática e a arte, sendo este último o que escolhemos para trilhar. Neste caso, ao adentrar por este caminho nos encontramos com o artista modernista português Almada Negreiros, suas obras e sua íntima relação com a matemática. A seguir, faremos um relato sobre este encontro.

\footnotetext{
${ }^{2}$ Também conhecido como Movimento Maker.
} 


\section{Um encontro de pesquisas sobre Almada Negreiros}

Nosso primeiro encontro com a arte de Almada deu-se a partir da obra Livro de Problemas de Almada Negreiros, em que Pedro J. Freitas e Simão Palmeirim Costa (2015), em que os autores analisam alguns elementos matemáticos presentes em uma série de desenhos do artista que, "apesar de o autor ter como intenção primeira produzir obras de arte, muito do seu trabalho pode ser apreciado matematicamente" (FREITAS; COSTA, 2014, p. 1). Neste livro, Freitas e Costa (2015) destacam que no espólio do artista há uma coleção de desenhos com conteúdo exclusivamente geométrico, com construções envolvendo o número de ouro, a divisão da circunferência em nove partes, a $\sqrt{5}$, entre outros.

Em um estudo sobre os trabalhos de Almada Negreiros, Mendes (2017) discorre sobre o trabalho de Freitas e Costa (2015), enfatizando que esses autores se dedicaram à análise sistemática dos esboços geométricos de Almada Negreiros, tendo como aliadas a Matemática e a Arte, um estudo moroso e minucioso, para depois poderem reconstituir e identificar os vários elementos presentes, as suas construções geométricas com apoio no Geogebra.

Igualmente, Mendes (2017) destaca, ainda, que o trabalho de Freitas e Costa (2015) permite aos leitores perceberem que existem, na obra de Almada Negreiros, dois tipos de construções: as exatas, as quais foram demonstradas matematicamente pelos dois autores do estudo e que se poderiam denominar "Teoremas de Almada", e as aproximadas, para as quais calcularam o erro, muito vezes na ordem de um milésimo, portanto surpreendente boas - a espessura do lápis seria maior do que o erro cometido no traço.

É importante ressaltar que o trabalho de Mendes (2017) se localiza na confluência epistemológica entre um triângulo epistêmico formado pela relação integrativa entre Arte, História, Matemática em busca de conexões com as abordagens didáticas para o ensino de Matemática, o que se aproxima de nossas intenções neste artigo, com o acréscimo da inclusão das tecnologias de informação e comunicação, conforme já mencionamos anteriormente.

Nesse sentido, Mendes (2017) destaca que o tema principal das obras de Almada Negreiros foi o número, a geometria (Sagrada) e os seus significados. Neste sentido o artista revela-se como um neopitagórico, e talvez esse tenha sido o princípio filosófico que the forneceu a fonte mais profunda da sua inspiração, da sua criatividade e da sua "loucura" 
central refletida na sua arte geonumerática ou aritmogeométrica ${ }^{3}$. Nesta perspectiva de trabalho, Mendes (2017) destaca como exemplos os trabalhos de Lucília Barata (2005) em sua obra EspaçoNumerática ou nos trabalhos de Paulus Gerdes (2010) em suas representações das artes etnomatemática como arte-design e matrizes cíclicas.

\section{Almada Negreiros: a pessoa, o artista e sua arte matemática}

José Sobral de Almada Negreiros nasceu em São Tomé (África), em 1893, viveu em Portugal e revelou-se como um artista e um escritor polifacetado. Artista plástico, poeta, ensaísta, romancista e dramaturgo, associou-se em 1913 ao grupo modernista tendo vindo a formar, com Fernando Pessoa e Sá-Carneiro, o grupo da revista Orpheu. Faleceu em 1970, em Lisboa. O que nos chama atenção em Almada Negreiros é a sua própria história de vida. Filho do tenente de cavalaria António Lobo de Almada Negreiros e de Elvira Sobral de Almada Negreiros, destacou-se no universo artístico do século XX através da sua dedicação à literatura e participou de forma ativa no grupo ligado à Revista Orpheu, responsável pela introdução do Modernismo nas Artes e Letras em Portugal e enquanto artista, destacou-se por sua atuação multidisciplinar, tendo suas perpassando vários campos da arte, tais como a poesia, dramaturgia, pintura, desenho, entre outros. Além disso, foi um artista essencialmente autodidata, pois não frequentou qualquer escola de ensino artístico.

Em 1911, com apenas 14 anos de idade, Almada Negreiros apresenta o desenho intitulado $A$ Sátira, que utiliza traçados simples na composição da obra, porém em 1925, os trabalhos de Almada começam a apresentar elementos matemáticos de modo muito particular e original. Almada introduz na obra um tipo de pavimentação geométrica, como ilustra a obra Desenho à Lápis de Arlequim (figura 1a). Este tipo de composição aparecerá em várias obras que retratam diferentes contextos, como ilustra a famosa obra Retrato de Fernando Pessoa (figura 1b).

\footnotetext{
${ }^{3}$ Para Mendes (2017) a arte geonumerática ou aritmogeométrica refere-se às artes visuais encarnadas pelas relações concebidas noa integração da criatividade extraída das representações geométricas em números e das representações numéricas em formas para produzir expressão estética em Matemática. 
Figura 1. Retrato de Fernando Pessoa

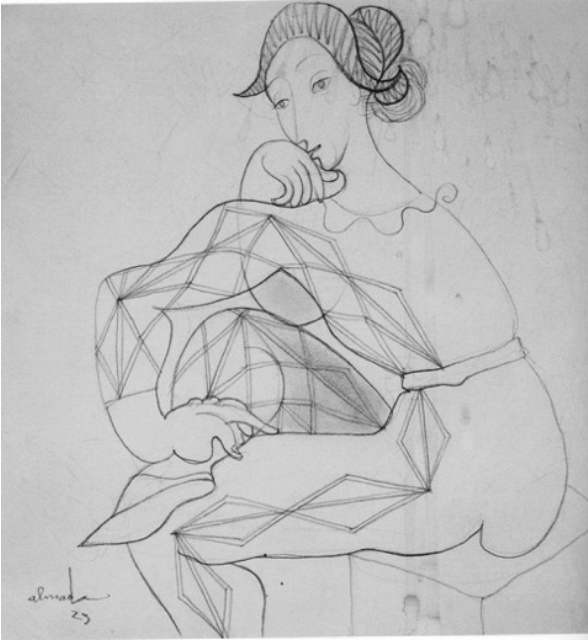

(a)

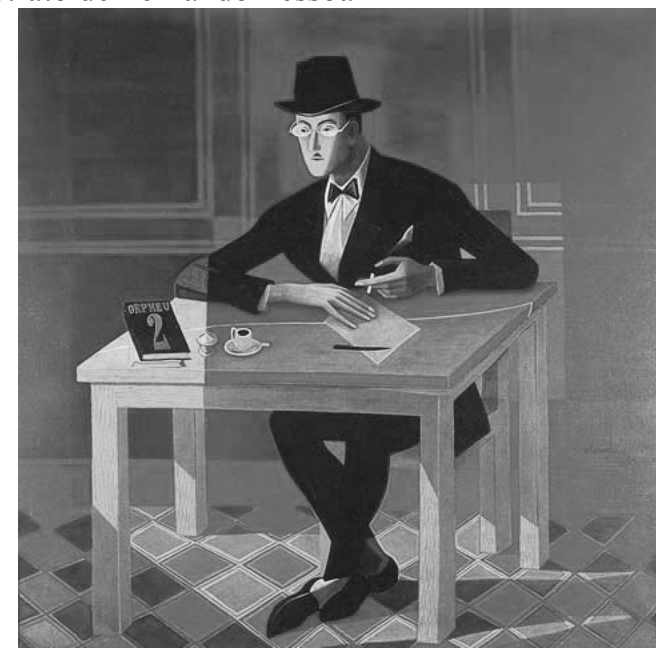

(b)

Fonte: https://bit.ly/2TO9IFq

A partir de 1957, alguns trabalhos de Almada apresentam uma tendência mais abstrata. Ele produziu quatro pinturas abstratas, sem moldura, pintadas em preto e branco, intituladas $A$ porta da Harmonia (figura 2a), O ponto da Bauhütte (figura 2b), Quadrante I (figura 2c) e Relação 9/10 (figura 3d).

Figura 2.

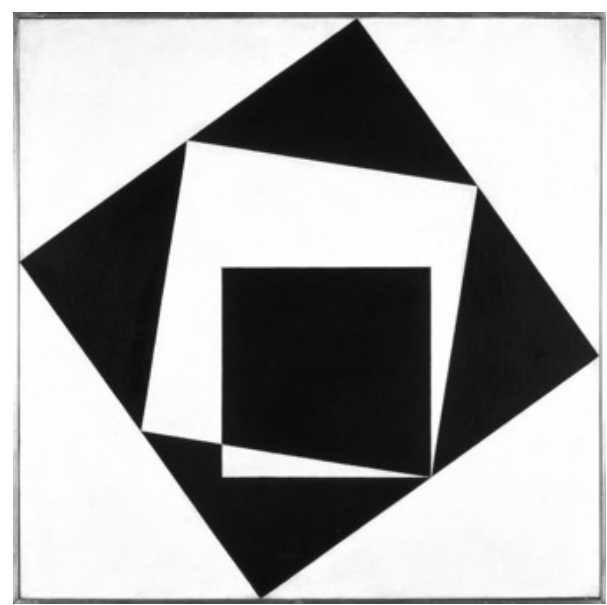

(a)

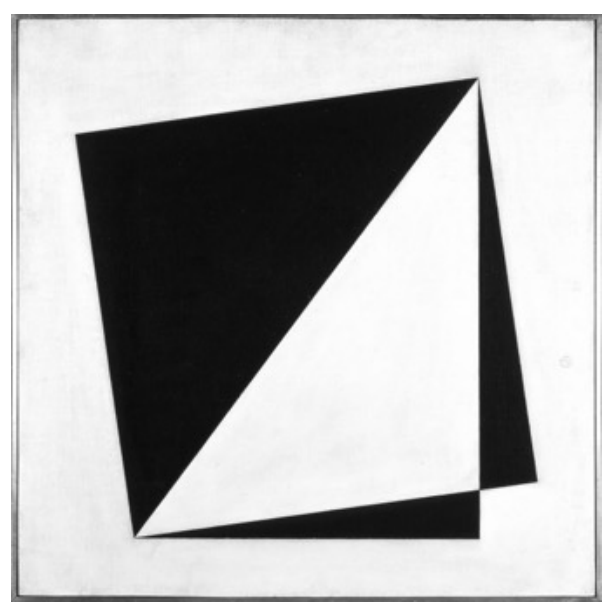

(b) 


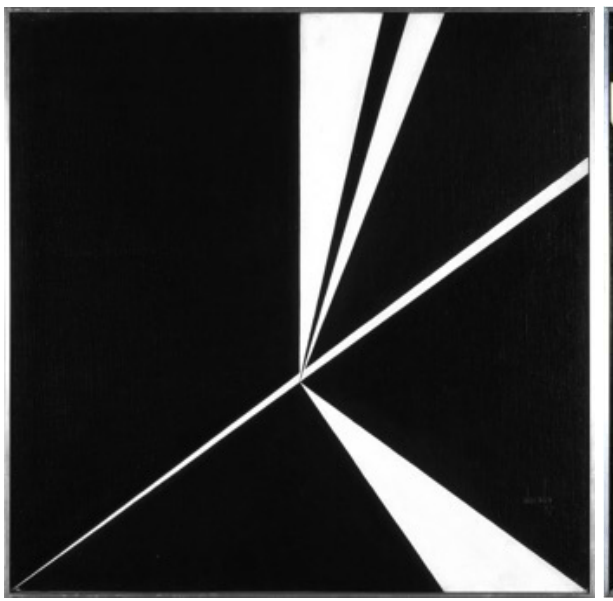

(c)

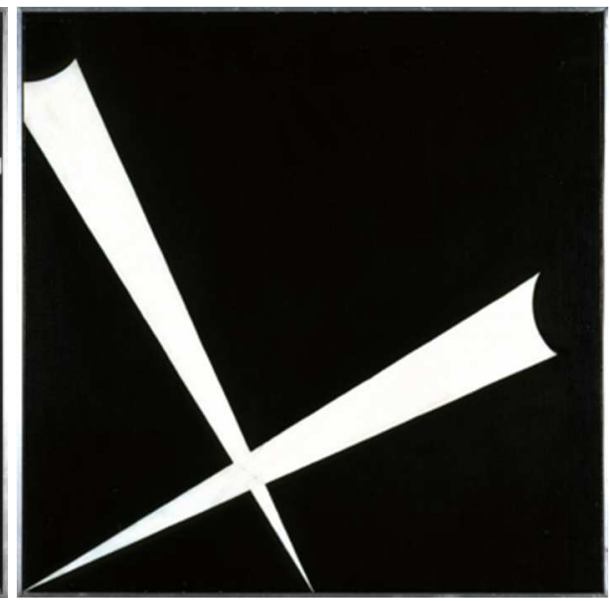

(d)

Fonte: Fundação Calouste Gulbenkian.

É possível perceber a forte presença geométrica nestas obras de Almada Negreiros, que surge por influência dos painéis de Nuno Gonçalves ${ }^{4}$, expostos nos Museu Nacional de Arte Antiga, em Portugal. Freitas (2016, p.136), afirma que Almada teria visitado esta exposição e ficado fascinado não só com os painéis, mas também com o Ecce Homo, uma obra também renascentista, que naquele tempo era atribuído a Nuno Gonçalves. Com este fascínio e sua dedicação em estudar o Ecce Homo e as várias relações matemáticas, de modo a compreender relações de proporção na pintura e relacioná-la a outros elementos geométricos, tais como o quadrado e a circunferência, Almada produz uma série obras várias referências matemáticas, como por exemplo, o Estudo de Almada para um altar do mosteiro da Batalha (figura 3) e a tapeçaria intitulada $O$ Número (figura 4), produzida em 1958 e exposta no Tribunal de Contas de Lisboa.

\footnotetext{
${ }^{4}$ Nuno Gonçalves foi um pintor português do século XV.
} 
Figura 3. Estudo de Almada para um altar do mosteiro da Batalha

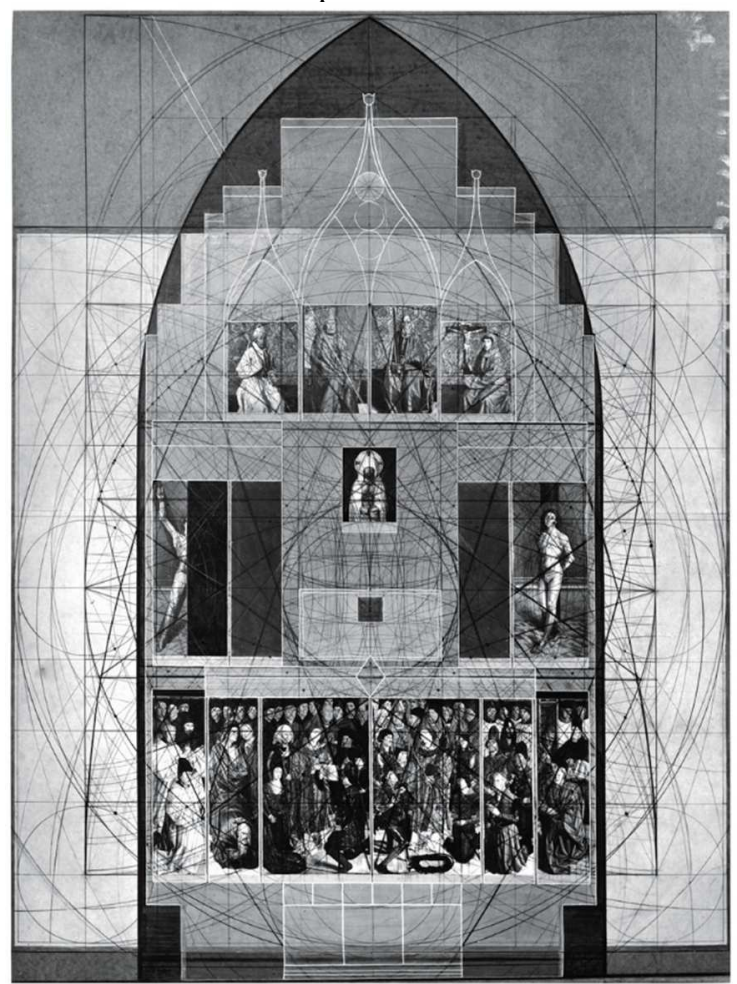

Fonte: https://bit.ly/2FRm3VY

Figura 4. O Número

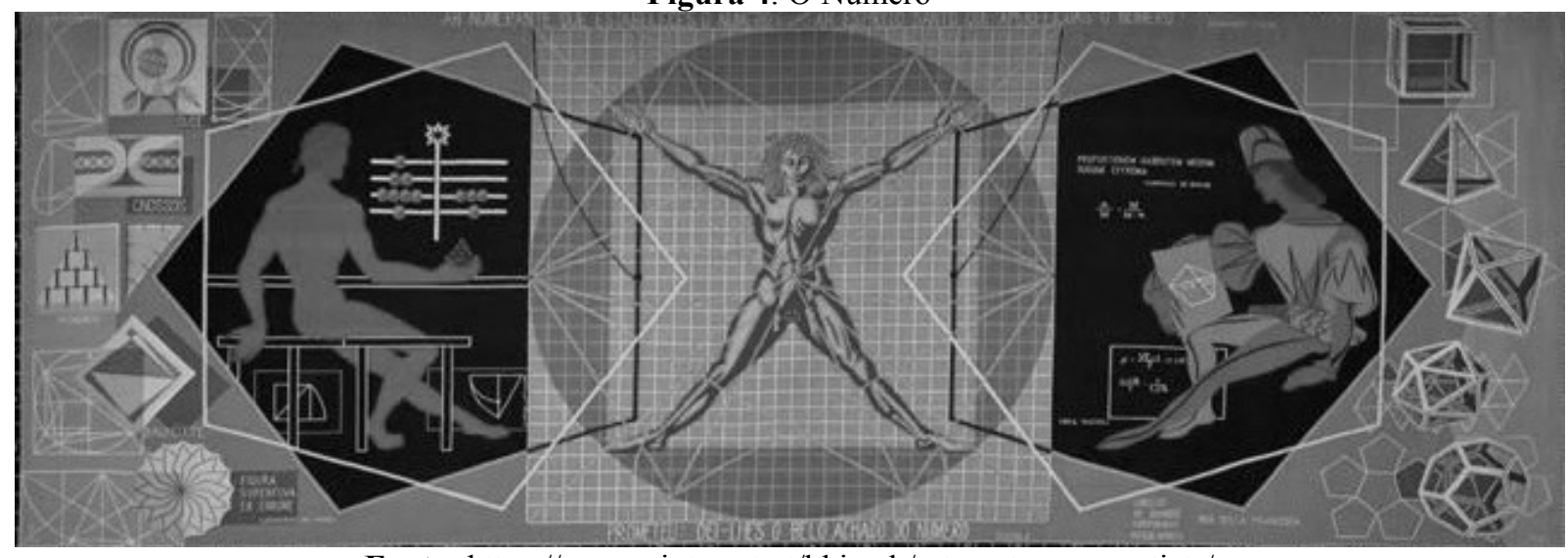

Fonte: https://www.pinterest.pt/bhimab/art-portuguese-artists/

A riqueza de detalhes desta, em específico, nos instigou a buscar interseções e conexões entre a matemática e arte. Na área central da tapeçaria (figura 5a), há um homem de braços e pernas abertos em X, enquadrado e inscrito num círculo sobre uma tela quadriculada, em referência não ao Homem Vitruviano (figura 5b), de Leonardo da Vinci, mas em referência ao Homo ad circulum (figura 5c), de Cesare Cesariano. De acordo com Aniello (2007, p. 338), "o desenho central da tapeçaria de Almada é uma exata cópia do desenho de Cesariano", porém com uma marca pessoal do artista ao desenho de Cesariano: dois retângulos oblíquos e 
cujo centro encontra-se no umbigo do homem. Ainda na área central da tapeçaria, há também duas inscrições, uma no topo e outra na base.

Figura 5. Comparação entre a obra de Almada, Da Vinci e Cesare.

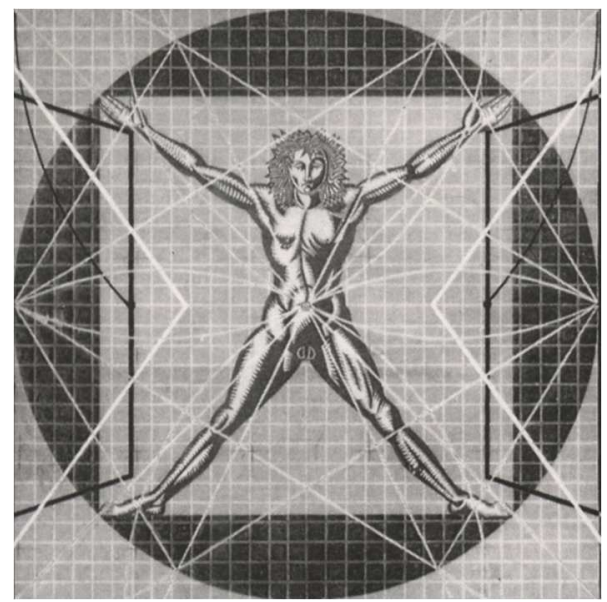

(a)

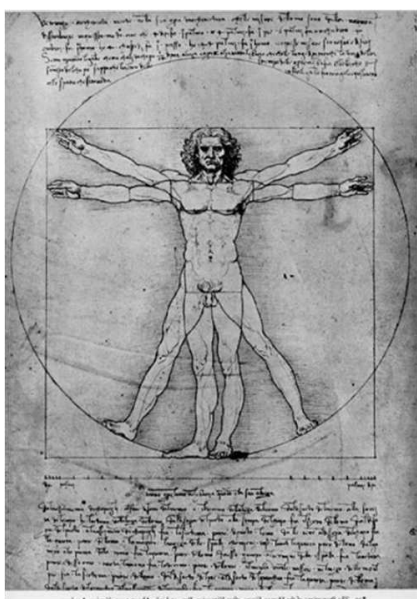

(b)

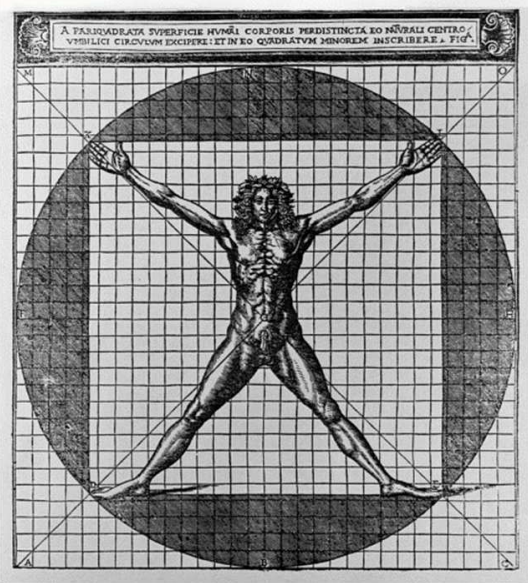

(c)

Fonte: https://bit.ly/2uEmVGQ

No topo, tem-se a frase Ah! Numerante que estabeleces o Número!/ Ah! Espírito Santo que aperfeiçoas o Número!, do escritor, filósofo, poeta renascentista e missionário catalão Raimundo Lúlio. Na base, tem-se a frase "Prometeu: dei-lhes o belo achado do número", um pensamento do dramaturgo grego Ésquilo.

Ao lado do homem central na tapeçaria, existem duas figuras humanas: à esquerda um homem grego (figura 6a) e à direita um homem renascentista (figura 6b), ambos emoldurados por dois pentágonos. Ao lado do homem grego, há cinco elementos: o Vaso de Susa, um friso do Palácio de Cnossos, a Tetraktis Pitagórica, o Ponto de Bauhütte e a Figura Supérflua ExErrone. O Vaso de Susa é uma peça produzida entre os anos 4.000 e 3.500 antes de Cristo na Babilônia, que encontra-se no Museu do Louvre, em Paris. Os frisos do Palácio de Cnossos, representa época grega da idade do Bronze. A tetraktis ilustra representação dos números através de uma figura geométrica muito estudada pela escola pitagórica. O ponto de Bauhütte ilustra um problema, proposto em versos medievais, no livro Le Nombre d'Or, de Matila Ghyka, por construtores de catedrais que formavam uma associação chamada Bauhütte e, finalmente, a Supérflua Ex-Errone reproduz um desenho de Leonardo da Vinci, que aparece no livro De divina proportione de Luca Pacioli. 
Figura 6. Figuras humanas na tapeçaria.

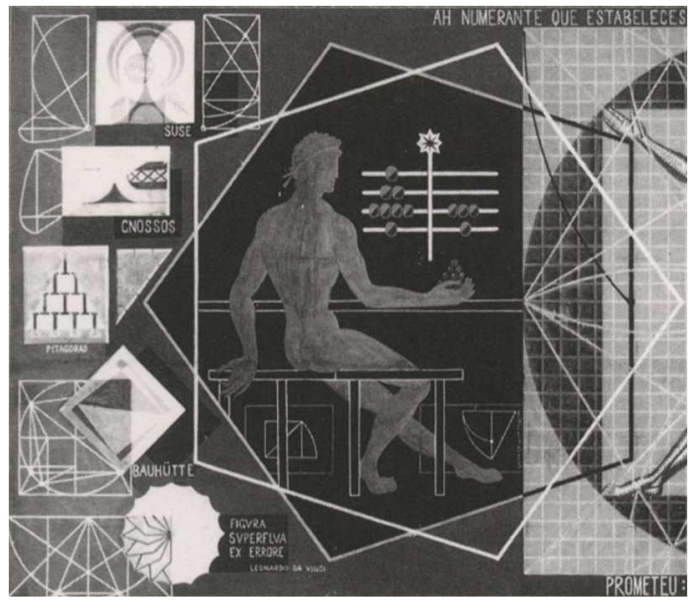

(a)

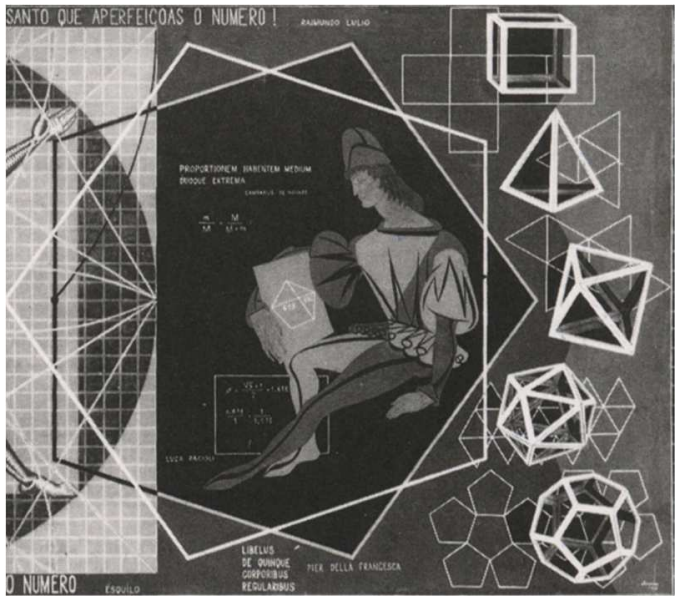

(b)

Fonte: adaptação dos autores.

Ainda, ao redor do homem grego, Aniello (2007, p. 340), aponta a possível representação de Homero, Euclides e Pitágoras, a partir dos teoremas desenhados nos pés do homem grego e do ábaco na direção de uma das suas mãos. Freitas (2016, p. 139) acrescenta a esta análise, que estas referências seguem uma certa ordem cronológica.

Já o homem à direita, encontra-se a representação do homem renascentista, que possui à sua volta os cinco sólidos de Platão com suas respectivas planificações, que se contrapõem aos cinco elementos ao redor do homem grego. Almada também refere-se aos matemáticos Campanus de Novara, que traduziu do árabe e publicou uma versão dos Elementos de Euclides, Luca Pacioli, conhecido por sua obra De Divina Proportioni e Piero della Francesca, que também era pintor, ficou conhecido pelos seus trabalhos com a técnica da perspectiva. Ao lado deste último, aparece a frase "De quinque corporibus regularibus", que significa "os cinco corpos regulares". Por último, o homem renascentista segura uma placa que representa o número de ouro através da interseção de duas diagonais de um pentágono regular.

Freitas (2016, p. 139) aponta que as escolhas dos elementos e desenhos na obra, "são reflexo daquilo que Almada chamava o cânone", que possui algumas constantes e que permeiam não somente a Idade Média, mas todas as épocas. Com relação ao conteúdo deste cânone, a partir da análise das entrevistas de Almada, Freitas (2016, p. 141) explica que 
relação (em geral, uma circunferência inscrita no quadrado), a razão de ouro (média e extrema razão) e a famosa relação nove/dez, que se refere ora às divisões da circunferência em nove e dez partes, ora à razão $9 / 10$.

Assim, Almada expressa na obra $O$ Número a evolução temporal de alguns elementos deste cânone, através das construções geométricas que acompanham os desenhos ao redor do homem grego e do renascentista.

Há também no rol de obras de Almada, a criação de um grande painel, datado do final da década de 60, que decora a parede da Fundação Calouste Gulbenkian, em Lisboa. Esta obra, denominada de Começar (figura 7), reúne uma série de estudos geométricos e alguns elementos do cânone.

Figura 7. Começar.

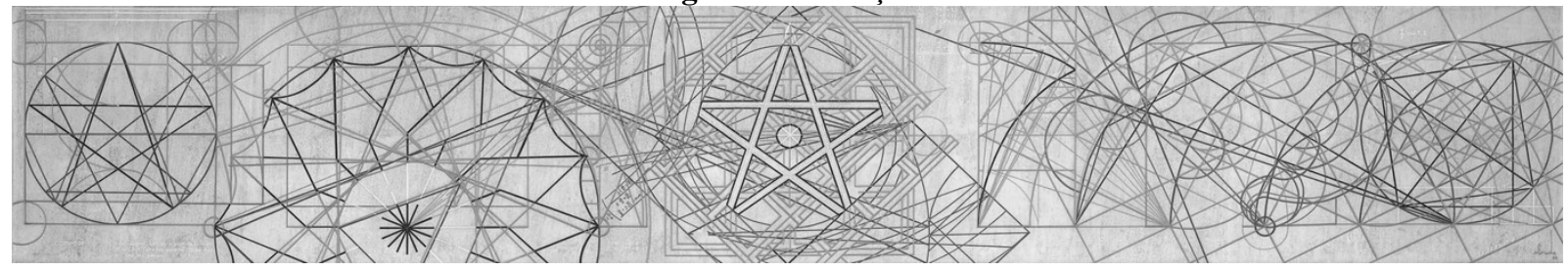

Fonte: Fundação Calouste Gulbenkian.

Começar é uma obra emblemática de Almada e sua grandiosidade se traduz na complexidade geométrica desta obra. Se dividirmos este painel em cinco partes, da esquerda para direita, encontraremos os seguintes elementos:

1) Estrelas pentagonais: observa-se três pentagramas de cores diferentes, inscritos numa circunferência;

2) Figura superflua Ex-errore: A grande estrela de 16 pontas, chamada Figura Superflua Ex-Errore, é inspirada numa ilustração de Leonardo da Vinci para o livro De divina Proportione de Luca Pacioli;

3) Grande estrela central: uma estrela de cinco pontas, numa moeda dos tempos de D. Afonso Henriques;

4) Divisões da circunferência: geometrização de uma figura simbólica da cultura grega, um machado duplo, que é a base para propostas da divisão da circunferência em partes iguais; 
5) Ponto de Bauhütte: uma construção da autoria de Almada que pretende determinar geometricamente o ponto comum a uma circunferência, um quadrado e um triângulo.

Embora Começar seja umas das obras mais conhecidas de Almada e com forte presença geométrica, o artista também produziu muitas outras obras com teor matemático, tais como dois afrescos que estão na Universidade de Coimbra, intitulados Matemática Universal (figura 8), em que o artista revela seu conhecimento sobre a história da Matemática, representando ali quatro períodos distintos: Antiguidade, a Idade Média, a Idade Moderna e a Época Contemporânea.

Figura 8. Matemática Universal.

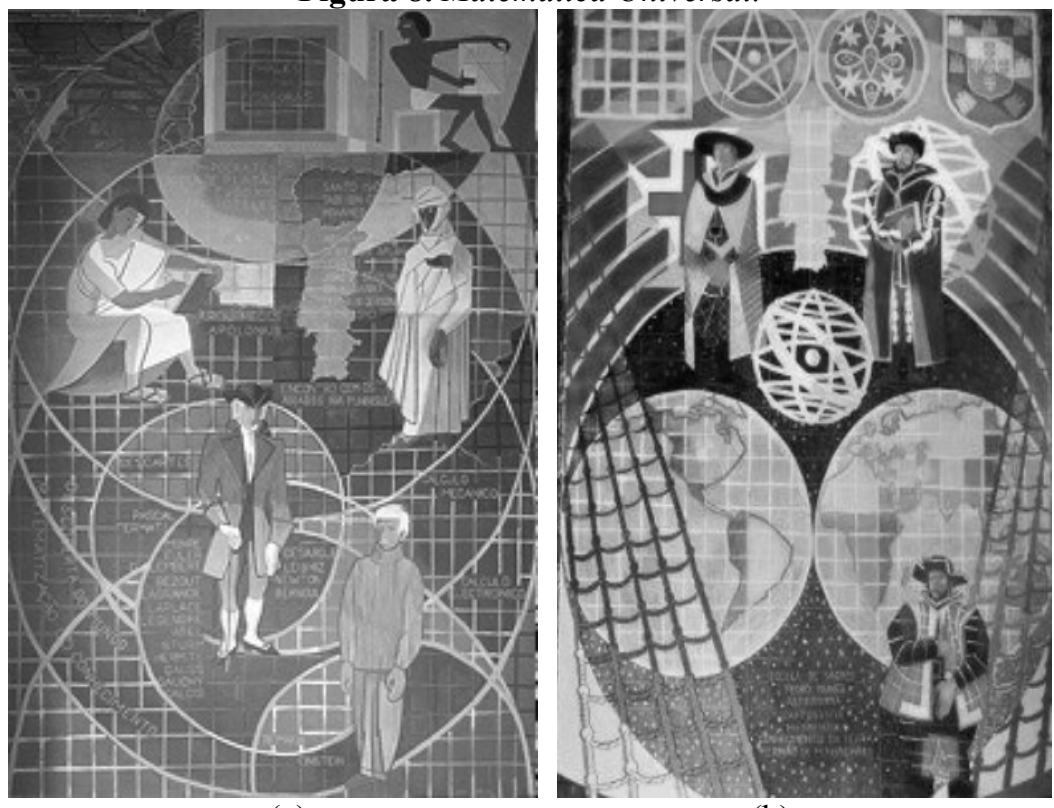

(a)

Fonte: Vaz (2008)

(b)

Sobre estes afrescos, Vaz (2013, p. 76) destaca:

Almada optou por prescindir de algarismos ou fórmulas, recorreu essencialmente ao desenho figurativo, ao signo linguístico (a avaliar pela quantidade de texto presente no painel da esquerda) e também à figuração geométrica. Ainda se podem observar elementos comuns aos dois frescos, sendo a circunferência o elemento mais utilizado, como centro definidor de ambas as composições, mais evidente na da esquerda. Sobressai também, em ambos, o fundo quadriculado. (VAZ, 2013, p. 76) 
Após este estudo mais aprofundado sobre Almada Negreiros, percebemos o caráter interdisciplinar de sua arte, mas compreender isto não é suficiente. Como isto se traduziu em uma aprendizagem criativa? Nesta pesquisa, o produto de estudo aprofundado, que aqui chamaremos de curar se traduziu em uma produção autoral, denominada de fazer. Sobre o Curar e Fazer, recorremos a Vaz e Rocha (2018), que definem o curar como uma curadoria de conteúdo, através de uma imersão interdisciplinar, em que haja descobertas, seleção, categorização, e organização de conteúdos capazes de contribuir para o entendimento dos principais conteúdos abordados no contexto artístico e matemático. Por sua vez, o fazer consiste em interpretar as curadorias realizadas, conectando a Matemática e a Arte. Estas interpretações podem ser materializadas em produtos criativos, de diferentes formatos, tais como poemas, jogos, atividades lúdicas, produções digitais, animações, peças 3D, Guias, ebooks ou releituras interdisciplinares de imagens, entre outros. Neste caso, o fazer atrelado à curadoria sobre Almada Negreiros se traduziu em um livro digital ${ }^{5}$, para apresentar o artista e sua arte, de modo que fosse possível identificar como a Matemática e a Arte se entrelaçam (figura 9). Este livro digital consta dos seguintes capítulos: Uma breve biografia de Almada Negreiros, As principais obras do artista e A matemática na arte de Almada.

Figura 9. Livro digital sobre Almada Negreiros.

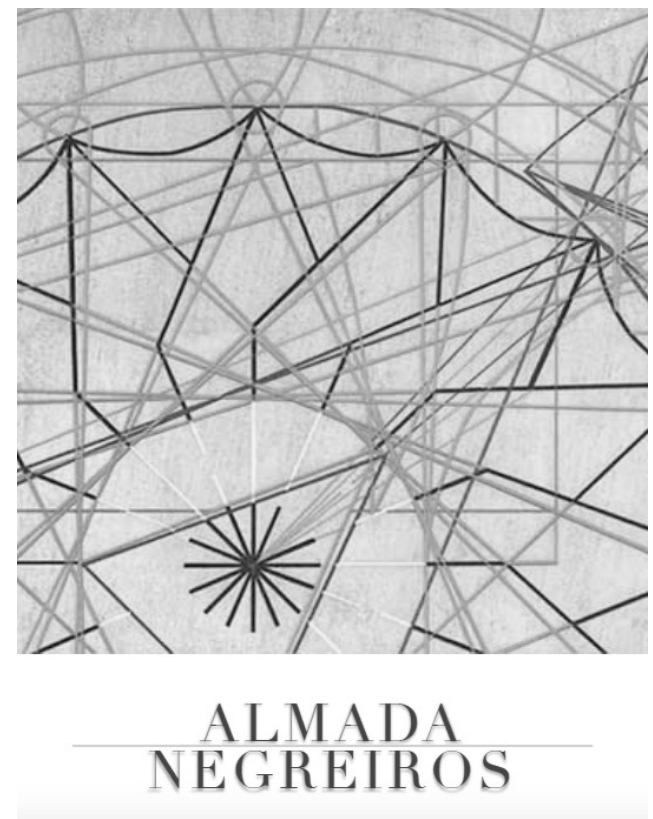

Fonte: Os autores.

${ }^{5}$ Disponível em: http://repositorio.ufpa.br/jspui/bitstream/2011/12172/2/Produto_AlmadaNegreiros.pdf 
Durante a elaboração deste livro digital, um novo produto atrelado ao fazer criativo a partir das obras de Almada Negreiros foi elaborado, uma animação elaborada no Geogebra sobre a obra $O$ ponto da Bauhütte (figura $2 \mathrm{~b})^{6}$, uma animação com base em uma construção do atribuída a Lima de Freitas, em Vaz (2013), o qual descreveremos a seguir.

Sobre uma reta, marcamos os pontos A e B e construímos uma semicircunferência que passe pelos pontos. Sobre a reta, marcamos ponto C, ponto médio de AB. Com extremos em C e na semicircunferência, traçamos a perpendicular ao segmento AB. Determinamos os pontos médios dos raios da circunferência com extremos A e B, respectivamente. Em seguida, traçamos uma semicircunferência de centro no ponto médio de $\mathrm{CB}$ ao qual pertence o ponto médio de $\mathrm{AC}$. Traçamos três segmentos de reta perpendiculares à reta $\mathrm{AB}$ aos quais pertencem os pontos médios de $\mathrm{AC}$, de $\mathrm{CB}$ e $\mathrm{B}$, respectivamente, em que o extremo oposto intersecta a semicircunferência e encontramos o ponto médio do segmento de reta FJ. Traçamos a circunferência de centro no ponto médio de JF e que passa pelos pontos J e F. Desenhamos o segmento de reta DF, BJ e CJ.

Figura 10. Construção geométrica do Ponto de Bauhütte.

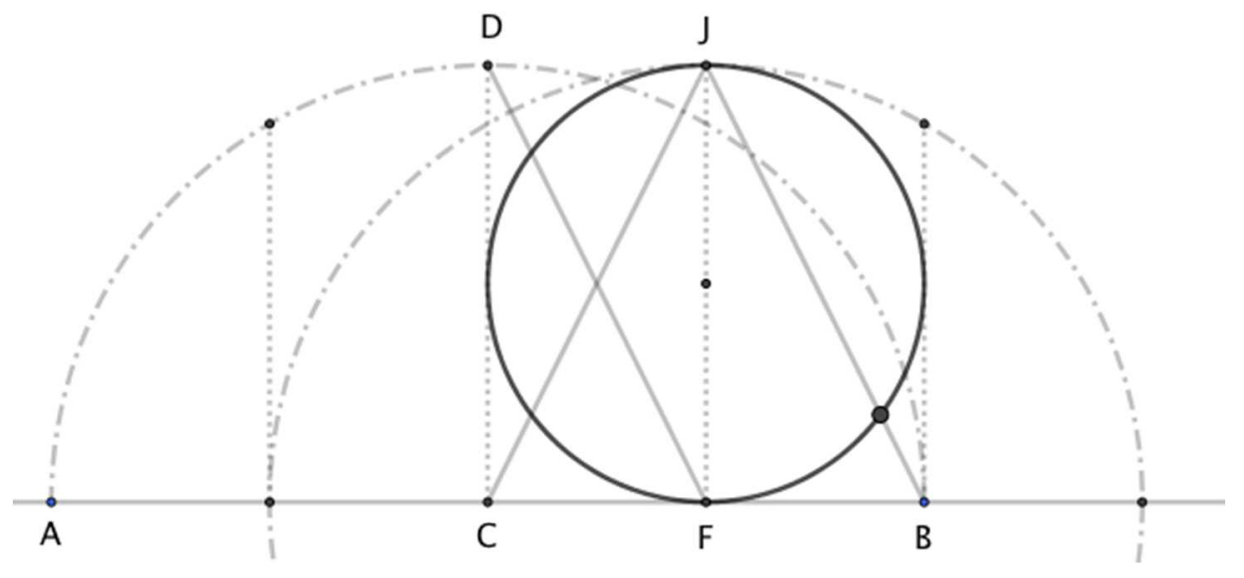

Fonte: Os autores.

Encontrar os pontos $\mathrm{N}$ de interseção do segmento $\mathrm{BJ}$ com a circunferência e $\mathrm{P}$ de interseção do segmento DF com a circunferência. Desenhamos o segmento PN que passa no centro da circunferência e o segmento $\mathrm{QR}$, que é perpendicular a PN e passa pelo centro da circunferência, L. Desenhamos o quadrado de vértices PQRN, inscrito na circunferência.

${ }^{6}$ Disponível em https://www.geogebra.org/m/bexyDnjy. 
Traçamos o segmento RT, que é perpendicular a $\mathrm{AB}$ e cujos extremos pertencem à circunferência. Finalmente, desenhamos o segmento TQ, obtendo assim o triângulo retângulo QTR. Obtemos assim o traçado de Almada da construção do Ponto da Bauhütte.

Figura 11. Construção do Ponto de Bauhütte.

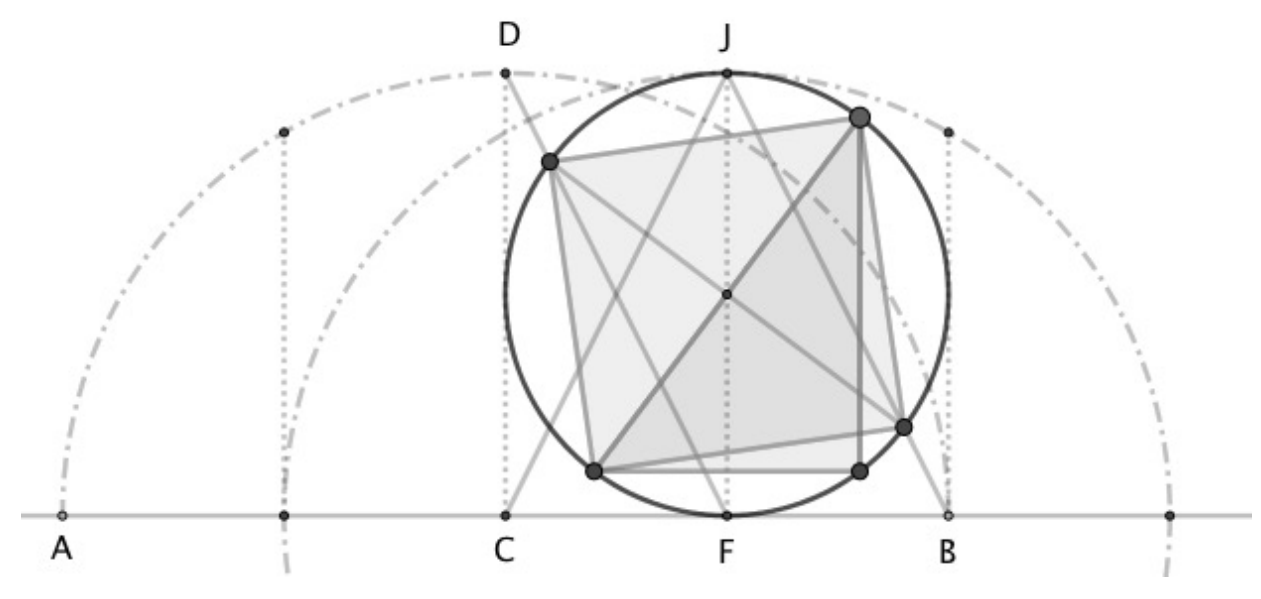

Fonte: Os autores.

A partir dessa construção, identificamos como Almada Negreiro usou a construção do ponto de Bauhütte para compor a sua obra. O artista manteve o quadrado vermelho e o triângulo azul da figura 12, estes são os elementos principais da construção do ponto de Bauhütte: um ponto que é o vértice comum de um quadrado e um triângulo inscritos em uma circunferência. Além disso, o artista pintou estes elementos de modo muito especial: a interseção do triângulo com o quadrado pintou de branco; a parte do triângulo que não intercepta o quadrado, ele pintou de preto; a parte triangular formada pela diagonal, onde não encontra-se o triângulo azul, pintou de preto e o que restou do quadrado também pintou de preto. 
Figura 12. O Ponto de Bauhütte - Reconstrução no software Geogebra.

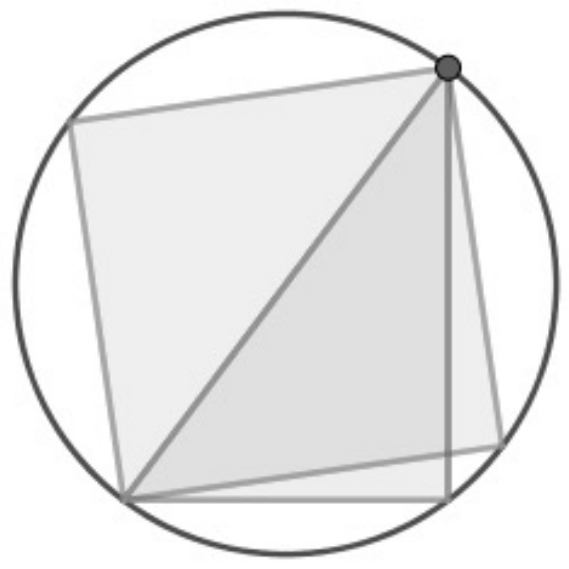

(a)

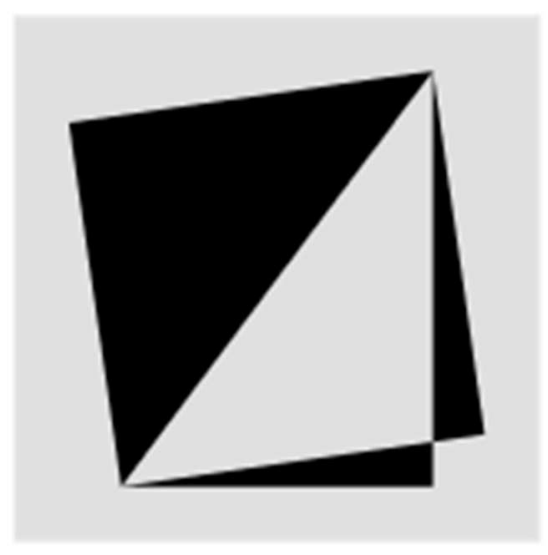

(b)

Fonte: Os autores.

Sobre este processo de Curar \& Fazer, salientamos todo seu caráter interdisciplinar, envolvendo a matemática e arte e que nos permitiu refletir sobre ele, já que em uma pesquisa cartográfica, é fundamental que o pesquisador cartografe os processos em curso, com a máxima atenção sobre eles, em vistas de estabelecer um diálogo entre eles, traduzindo não apenas o produto final, mas também o processo como um todo. Com isto, nossa reflexão sobre todo esse processo nos levou a uma nova possibilidade, ou melhor, enxergamos um novo caminho, que trilharemos a seguir.

\section{A guisa de reflexões finais acerca da conexão entre História, Matemática e Arte}

Ao iniciar este artigo, afirmamos que partiríamos de um lugar construído pela experiência, com múltiplas entradas e saídas e que nos proporcionou encontros com a aprendizagem criativa através da Matemática e da Arte. Entretanto, novos caminhos surgiram, instigando-nos a trilhar e vivenciar um novo encontro, neste caso, um encontro com a História da Matemática. A respeito dessa afirmação, argumentamos ao longo do artigo, sobre a potencialidade da Arte de Almada Negreiros como conexão entre História, Matemática e Arte.

Para tanto, o método da cartografia, enquanto opção metodológica para esta pesquisa, nos proporcionou estabelecer conexões entre processos em curso e/ou entre novos processos que emergem diante do pesquisador-cartógrafo em seu caminhar. Desta forma, a atenção do cartógrafo diante de tudo que lhe cerca é o cerne da pesquisa cartográfica, como afirma Souza e Francisco (2016, p. 816), pontuando que o coração da pesquisa está na qualidade do 
funcionamento da atenção do pesquisador, no sentido que o pesquisador não está em campo para coletar dados que já estão prontos, mas estar atento aos dados que são produzidos ao longo da pesquisa. É diante desta possibilidade, de voltar-se aos novos processos que surgem, nossa atenção se voltará para um encontro com a História da Matemática, que surgiu como corolário de nossa busca pela aprendizagem criativa em matemática, através de um processo interdisciplinar com a arte.

Ao acompanharmos o processo de aprendizagem criativa em matemática a partir das obras de Almada Negreiros, buscávamos responder a seguinte questão: como a integração de saberes elou abordagens da Matemática e da Arte pode promover uma aprendizagem criativa? A resposta para esta questão perpassou, dentre outras coisas, pela interdisciplinaridade, compreendida aqui como um processo para vencer a fragmentação dos processos de produção e socialização do conhecimento, de forma a recuperar o caráter de unidade, síntese, totalidade e integração dos saberes (Thiesen, 2007). Com este entendimento, a consolidação da interdisciplinaridade surgiu como uma atitude, ou melhor, como uma postura interdisciplinar, em que prevalece o diálogo entre a matemática e a arte, na compreensão que, isoladamente, ambas as ciências são limitadas.

É a partir desta compreensão de incompletude diante do isolamento é que buscamos neste processo todo, aproximar a matemática e a arte e transitar entre suas fronteiras ou zonas mistas ${ }^{7}$. Esta aproximação interdisciplinar ocorreu tendo a História da Matemática como plano de fundo, pois sem ela, como seria possível entender a arte de Almada Negreiros sem adentrar nas profundezas de suas inspirações? Como estabelecer conexões entre a geometria pitagórica e arte geométrica explicita em Começar? Como trazer à tona a evolução da matemática nitidamente expressa por Almada em O Número?

A respeito desta aproximação entre a matemática e a arte, pontuamos que ao longo da história, cada povo elaborou e vivenciou sua arte sob diversas influências, sejam elas ordem social, cultura, econômica, entre outras. Flores e Zago (2009), aprofundam esta discussão ao afirmarem que uma obra arte é a representação de uma forma de pensar em uma dada época:

Entender como cada povo pensou e pensa a elaboração de sua arte, ou como cada artista imerso em sua cultura cria arte, significa

\footnotetext{
${ }^{7}$ Entendemos aqui as zonas mistas como uma região de trânsito comum entre as duas áreas, no qual não é possível identificar explicitamente uma fronteira entre as duas áreas. 
compreender que a obra de arte não é a representação de algo em si, imanente e transcendental, mas de um campo de ideias e de conhecimentos possíveis àquela época, ou, pode-se dizer, de formas de pensamento. Além disso, significa ver que fomos criados, educados numa estética de beleza, rigor, harmonia onde a matemática funciona como o aparato técnico da representação artística. (FLORES; ZAGO, 2009, p. 339).

De fato, quando observamos o processo que percorremos com Almada Negreiros, percebemos que o artista representou em suas obras, as múltiplas forças que lhe influenciara, como fica explícito, por exemplo, na obra Retrato de Fernando Pessoa (figura 1b), que de um lado o artista apresenta o próprio movimento modernista ao retratar o poeta em sua mesa e sobre ela uma revista Orpheu, e de outro, a própria representação do desenho em perspectiva e a pavimentação geométrica do plano, o que evidencia o seu forte laço com a matemática. Ora, é natural estabelecer tais conexões entre a matemática e arte, tendo em vista que aquela está diretamente vinculada à atividade humana, como afirma D’Ambrosio (1999):

As ideias matemáticas comparecem em toda a evolução da humanidade, definindo estratégias de ação para lidar com o ambiente, criando e desenhando instrumentos para esse fim, e buscando explicações sobre os fatos e fenômenos da natureza e para a própria existência. Em todos os momentos da história e em todas as civilizações, as ideias matemáticas estão presentes em todas as formas de fazer e de saber (D’AMBROSIO, 1999, p. 97).

Ainda sobre esta investigação interdisciplinar, foi possível perceber que Almada trouxe para sua arte todo o conhecimento matemático que construíra ao longo de sua vida, culminando na obra Começar, em que o artista conecta uma série de construções geométricas e as suas várias referências culturais. Isto aproxima-se ao que Mendes (2008) indica sobre a manifestação da matemática na arte:

Ao longo de sua existência, a sociedade humana construiu uma variedade cultural que se manifesta por meio de atividades relacionadas à arte e que podem ser interpretadas como uma aplicação de conceitos e técnicas geométricas, principalmente aquelas cujos princípios geométricos são centrais na construção de um desenho ou projeto artístico. A partir desse ponto de vista é possível percebermos o quanto a matemática é útil, tanto para a arte como para a ciência e a tecnologia (MENDES, 2008, p.38). 
Destacamos também que o caminho que trilhamos sobre a aprendizagem criativa através da matemática e arte, fez-nos perceber que ao longo deste processo todo, a História da Matemática se fez presente e foi importante para a construção do conhecimento. Isto levounos às reflexões de Mendes (2017) acerca da história para o ensino da matemática, em que a partir de sua experiência, constatou que usar a investigação no ensino da matemática oportuniza os alunos, dentre outras coisas, o exercício de debater ideias matemáticas e estabelecer relações com outras áreas do conhecimento, sendo assim, "uma das formas produtivas para se concretizar um ensino de matemática que oportunize uma educação autônoma, criativa e ampliadora da cognição humana".

Ao relatar esta experiência em que buscamos a aprendizagem criativa a partir da matemática e arte, nos deparamos com uma possibilidade metodológica que até então não se apresentava a nós, a história da matemática. Entendemos que a história da matemática é fundamental para compreender como a arte e a matemática se relacionam e como esta influencia os artistas e os movimentos de todas as épocas.

Apontamos aqui nossas primeiras impressões sobre este novo caminho que começamos a desbravar, porém acreditamos que estas ações interdisciplinares, permeadas pela história da matemática nos possibilita adotar uma mudança de atitude, rompendo com os muros da socialização do conhecimento e nos permite vivenciar novas experiências enriquecedoras, com vistas na construção do conhecimento de forma criativa, autônoma e aberta ao diálogo e aos novos desafios. Com isto, uma nova possibilidade de caminho se apresenta a nós: como o professor de matemática pode transpor esta experiência para a sala de aula, integrando a história da matemática, a tecnologia e arte? Não há uma resposta padrão para este questionamento, tendo em vista que a busca por esta resposta nos possibilitaria habitar em um novo e vasto campo de pesquisa. Entretanto podemos elencar algumas possibilidades para que o professor possa experimentar das ações interdisciplinares aqui apresentadas. Assim, propomos que o professor de matemática promova em sala de aula ações de investigação em matemática e arte, a partir de outros artistas, tais como Escher, Crockett Johnson, Kandinsky, Mondrian, Beatriz Milhazes, Athos Bulcão, Antônio Peticov, entre outros, integrando neste processo as tecnologias da informação e comunicação. Ao estabelecer estas conexões, o professor poderá mediar discussões subjacentes, em que seja possível refletir sobre como a história da matemática se faz presente em práticas sociais, culturais, artísticas, científicas, 
entre outras. Defendemos, portanto, que ao estabelecer este diálogo, o professor proporcionará aos alunos um ambiente favorável a uma aprendizagem criativa, reflexiva e significativa.

\section{Referências}

Aniello, B. (Dezembro de 2007). José de Almada Negreiros, do caos à estrela dançante. Artis.

D'ambrosio, U. (1999). A História da Matemática: questões historiográficas e políticas e reflexos na Educação Matemática. Em M. A. Bicudo, Pesquisa em Educação Matemática: concepções e perspectivas (pp. 97-115). São Paulo: UNESP.

Freire, P. (2011). Pedagogia da Autonomia: Saberes Necessários à Prática Educativa. São Paulo: Paz e Terra.

Freitas, P. J., \& Costa, S. P. (2014). Os problemas de matemática de Almada Negreiros. Boletim da Sociedade Portuguesa de Matemática, pp. 01-04.

Freitas, P. J., \& Costa, S. P. (2015). Livro de Problemas de Almada Negreiros. Lisboa: Sociedade Portuguesa de Matemática.

Freitas, P. J., \& Costa, S. P. (2016). Geometria, entre suporte e tema da obra de arte, em Almada Negreiros. Revista Convocarte, pp. 136-145.

G. Deuleze, F. G. (1995). Mil Platôs: Capitalismo e Esquizofrenia (Vol. 1). Rio de Janeiro: Editora 34.

Gerdes, P. (2010). Da etnomatemática a arte-design e matrizes cíclicas. Belo Horizonte: Autêntica Editora.

Júnior, E. d. (2019). Atos e Lugares de Aprendizagem Criativa em Matemática. Dissertação de Mestrado, Universidade Federal do Pará, Programa de Pós-graduação Criatividade e Inovação em Metodologias do Ensino Superior, Belém.

Mendes, I. A. (2008). Ensino de Conceitos Geométricos, Medidas e Simetria: Por uma Educação (Etno)Matemática com Arte. Revista Cocar, 2, pp. 35-47.

Mendes, I. A. (2017). Das Artes Geométricas e MatematiColagens em Almada Negreiros. $1^{o}$ Encontro Luso-Brasileiro do TEAR - Territórios Artísticos com a Matemática. Óbidos/Portugal: Universidade Aberta de Lisboa.

Mendes, I. A. (janeiro de 2017). História para o ensino da matemática: uma reinvenção didática para a sala de aula. Revista Cocar, 1, pp. 145-166.

Passos, E., \& Barros, R. B. (2015). A cartografia como método de pesquisa-intervenção. Em E. Passos, L. D. Escossia, \& V. Kastrup, Pistas do método da cartografia: Pesquisaintervenção e produção de subjetividade (Vol. 1, pp. 17-31). Porto Alegre: Sulina.

Pires, F. A. (2010). Criatividade no Processo de Amadurecimento em Winnicott. Dissertação de Mestrado, Pontifícia Universidade Católica de São Paulo, São Paulo.

Sakamoto, C. K. (2012). Criatividade e a construção da realidade contemporânea. Trama Interdisciplinar, 3, pp. 86-96.

Barata, Lucília (2005). EspaçoNumerática: uma linguagem científica e simbólica. Viana do castelo: Centro Holístico Internacional, 2005.

Souza, S. R., \& Francisco, A. L. (2016). O método da cartografia em pesquisa qualitativa: Estabelecendo princípios... desenhando caminhos... Atas CIAIQ, 2, pp. 811-820.

Thiesen, J. d. (julho de 2007). A interdisciplinaridade como um movimento de articulação no processo ensino-aprendizagem. Percursos, 8, pp. 87-102.

Tuan, Y. F. (2018). Uma perspectiva experencial. Geograficidade, 8, pp. 04-15. 
Vaz, C. L., \& Rocha, H. (2018). Matemática e Arte em trilhas, olhares e diálogos. Belém: Editaedi.

Vaz, R. M. (2013). COMEÇAR de Almada Negreiros Arte e o Poder Formatador da Matemática. Dissertação de Mestrado, Universidade Nova de Lisboa, Lisboa.

Winnicott, D. W. (1975). O Brincar: a atividade creiativa e a busca do eu (self). Em D. W. Winnicott, $O$ brincar e a realidade (pp. 79-93). Imago.

Winnicott, D. W. (2011). Vivendo de modo criativo. Em D. W. Winnicott, Tudo começa em casa (pp. 23-39). WMF Martins Fontes.

Zago, H. d., \& Flores, C. R. (novembro de 2010). Uma Proposta para Relacionar Arte e Educação Matemática. Revista Latinoamericana de Investigación en Matemática Educativa, pp. 337-354.

Autores

Cristina Lúcia Dias Vaz

Doutora em Matemática Aplicada (Universidade de Campinas - Brasil). Professora e Pesquisadora do Programa de Pós-Graduação Criatividade e Inovação em Metodologias de

Ensino Superior da Universidade Federal do Pará (PPGCIMES/UFPA/Brasil). Tem experiência na área de Matemática. $\mathrm{Na}$ área de ensino de Matemática atua principalmente nosd seguintes temas: tecnologias inovadoras no ensino superior, metodologia ativas, ambientes virtuais de aprendizagem e aprendizagem criativa em Matemática e Arte. Mais informações no Currículo Lattes: http://Lattes.cnpq.br/5829728118120411. ORCID: https://orcid.org/00000003-1583-6129.E-mail: cvaz@ufpa.br

Edilson dos Passos Neri Júnior Mestrado em Ensino pelo Programa de Pós-Graduação Criatividade e Inovação em Metodologias de Ensino Superior da Universidade Federal do Pará (PPGCIMES/UFPA/Brasil). Doutorando do Programa de Pós-graduação em Educação em Ciências e Matemática (PPGECM/UFPA/Brasil), na Área de Concentração Educação Matemática. Professor da Escola de Aplicação da Universidade Federal do Pará. Tem experiência na área de Ensino com ênfase em Matemática, Tecnologia Inovadoras no Ensino

Superior e Aprendizagem Criativa em Matemática e Arte. Para mais informações visitar o Currículo Lattes: http://Lattes.cnpq.br/5917661277687347. ORCID: https://orcid.org/0000-

0003-4422-7330. E-mail: neri@ufpa.br 